\title{
Home recording of PEF in young asthmatics: does it contribute to management?
}

\author{
K. Uwyyed, C. Springer, A. Avital, E. Bar-Yishay, S. Godfrey
}

\begin{abstract}
Home recording of PEF in young asthmatics: does it contribute to management? $K$ Uwyyed, C. Springer, A. Avital, E. Bar-Yishay, S. Godfrey. (CERS Journals Ltd 1996.

ABSTRACT: The value of home monitoring of peak expiratory flow (PEF) as part of an action plan for asthma management in children and young adults is uncertain. We sought to determine whether home recording of PEF benefited asthma management and whether any contribution was affected by the severity of the asthma.

Twenty-eight children and young adults with asthma of different severity (mean age 14 yrs; 95\% confidence interval (95\% CI) 12-16 yrs) recorded their symptoms, drug consumption and PEF twice daily for a mean of 82 days over a 12 week period, and attended the laboratory every 2 weeks for measurement of lung function.

The number of individual patients with significant correlations for laboratory lung function tests compared with ambulatory PEF and diary scores averaged over the preceeding 2 weeks was low in all severity groups. When measured in the laboratory, PEF meter readings correlated poorly with PEF measured by spirometry. The proportion of patients with significant correlations for PEF, symptoms and rescue bronchodilator use on a day-to-day basis was $70-80 \%$ in the group of severe asthmatics and significantly less in the mild asthmatics. In a subgroup of 14 patients who were sick on a mean of 19 days, the mean difference in PEF between well and sick days was $14 \%$ of predicted. Diurnal PEF variation correlated poorly with other parameters in all groups.

It is concluded that PEF monitoring adds little to daily recording of symptoms and bronchodilator use in the management of young patients with severe asthma, and it is too insensitive to register meaningful clinical changes in those with milder asthma.
\end{abstract}

Eur Respir J., 1996, 9, 872-879.

Institute of Pulmonology, Hadassah University Hospital, Jerusalem, Israel.

\author{
Correspondence: S. Godfrey \\ Institute of Pulmonology \\ Hadassah University Hospital \\ Ein Kerem, POB 12000 \\ Jerusalem 91120 \\ Israel
}

Keywords: Asthma in children

diary record

home monitoring

peak expiratory flow rate

Received: August 31995

Accepted after revision December 281995
Variation in lung function from day to day, spontaneously or in response to treatment, is characteristic of bronchial asthma but the ability of the patient to recognize the changes is often limited and objective evaluation is desirable. Because of its practicability and the generally accepted belief that it improves management, it is now common to recommend that patients with asthma monitor their lung function on a day-to-day basis by measuring their peak expiratory flow (PEF) with a simple device such as the mini-Wright peak flow meter. For example, since SLY et al. [1] found no correlation between symptoms recorded in the diary of asthmatic children and rescue bronchodilator use, they stated that "rational management of troublesome asthma requires the use of an inexpensive peak flow meter to provide objective measurements of lung function". For many years now, it has been accepted that asthmatics also have a much larger diurnal variation of lung function than normal subjects, and that this diurnal variation is greater in those with more severe bronchial hyperreactivity $[2,3]$.

In the international consensus guidelines for the management of chronic asthma in adults and the subsequent British version of the recommendations $[4,5]$, the self measurement of PEF is encouraged as a valuable guide to the severity of the asthma and, amongst other suggestions, a falling PEF or a PEF below $60 \%$ of predicted is suggested as an indication to take additional corticosteroid medication. Similarly, in the statement from the Paediatric Asthma Consensus Group [6], the role of PEF in diagnosis and management is emphasized and the group recommend that "lung function should be normalized with no excess of diurnal variation in peak expiratory flow rate". However, other studies have cast doubt on the reliability of PEF measurements as an index of asthma severity, and in a very thoughtful review CLARK et al. [7] noted that many studies lacked adequate controls, that any correlation between PEF and subjective assessments was often very weak, and that the value of PEF recording in improving control or compliance was often marginal. Serious questions as to the value of home monitoring of $\mathrm{PEF}$ as part of an action plan for asthma management have also been raised by CHARLTON et al. [8] from a study in general practice, and by MALO et al. [9] who found that diary records alone were as good as PEF recording in detecting asthma exacerbations.

Some of the controversy over the value of PEF recording may be due to its inability to detect obstruction residing mainly in the smaller airways. A discrepancy between home $\mathrm{PEF}$ recording and laboratory measurement of midexpiratory flow was noted by FERGUSON [10], who followed 
20 children for 16 weeks with daily recording of symptoms and PEF and measurements of lung function in the laboratory every 2 weeks. Out of 70 periods of 2 weeks, at the end of which forced expiratory volume in one second (FEV1) was reduced, the PEF had been normal throughout in 16\%; and out of 25 periods of 2 weeks in which the patients were asymptomatic and had normal values for PEF, the mid-expiratory flow rate was reduced in no less than $76 \%$. Ferguson [10] concluded that airway obstruction may be present in a large proportion of asymptomatic children with asthma who have normal $\mathrm{PEF}$, and suggested that frequent assessment of forced mid-expiratory (FEF25-75) is required. Over 27 yrs ago, CHAI et al. [11] showed that infrequent measurements of lung function in asthmatics could give a highly erroneous impression of severity because of the variability of the disease.

Because of doubt as to the relevance of home measurements of PEF in children and young people on the one hand, and the unreliability of infrequent measurements on the other, we decided to undertake a new study in order to determine whether home recording of PEF added to meaningfully management, and whether any such contribution was affected by the severity of the asthma.

\section{Subjects and Methods}

\section{Study design}

The study comprised 12 weeks of daily recording of symptoms, medication consumption and PEF in ambulatory young asthmatics. Patients attended the department for clinical evaluation and pulmonary function tests by spirometry at the start of the study, and every 2 weeks for 12 weeks, making a total of seven visits. At the first visit, the patient was supplied with a PEF meter and diary, and at each subsequent visit the PEF meter was checked, as described above, and the diary was inspected to be sure it had been completed correctly. Treatment was adjusted on an open basis in line with the objective of mimicking the normal clinical situation as closely as possible.

\section{Patients}

The subjects included 28 unselected nonsmoking children and young adults of whom 25 were 17 yrs of age or younger, one was aged 23 yrs and two aged 30 yrs (mean 14 yrs; 95\% confidence interval (95\% CI) 12-16 yrs). The three adults were well-known to the paediatric staff, had asthma which began in childhood, and followed a similar pattern to that seen in the children. All patients had a clinical diagnosis of asthma supported by the demonstration of at least a $15 \%$ change in FEV1 spontaneously or in response to bronchodilator administration in the previous 6 months. All patients (including the three young adults) were regularly attending the asthma clinic, and an attempt was made to recruit subjects with asthma of varying severity as defined by their usual medication: 1) mild asthma - patients using bronchodilators only as needed; 2) moderate asthma - patients taking daily prophylaxis with either nonsteroidal drugs or inhaled corticosteroids at a dose of $<500 \mu \mathrm{g} \cdot$ day $^{-1}$; and 3) severe asthma - patients taking daily prophylaxis with inhaled corticosteroids at a dose of $>500 \mu \mathrm{g} \cdot$ day $^{-1}$.

Subjects were only included if their disease was stable, having required no change in maintenance medication over the previous 3 months. That the disease was active was indicated by the need to take rescue bronchodilator medication (up to a maximum of four times in $24 \mathrm{~h}$ ) on at least two occasions within the previous month. Patients with other pulmonary or cardiac disorders were excluded. During the 12 weeks of the study, treatment was adjusted if necessary on an open basis. For the purposes of analysis, the final classification of asthma severity groups was made at the end of the study. Of the 28 patients, nine were classified as mild, nine as moderate, and 10 as severe. The ages, sex and baseline lung function of the subjects in the three groups are presented in table 1. All subjects were volunteers and the study was approved by the Local Ethics Committee. No experimental medications or treatments were involved.

\section{Data recorded at home}

The patients recorded asthma symptoms, medication consumption and PEF results in an asthma diary. Each patient was supplied with a new mini-Wright peak flow meter (Clement Clarke International Ltd, London, UK) and was instructed in its use. Only those able to use the meter reliably were included in the study. The meter was checked by one of the authors, who has a stable PEF, by measuring his own PEF with the meter to be sure that its reading was within his normal range. The patients were asked to measure their PEF twice daily at home, in the morning and in the evening, before taking any medication, and to record the best of three attempts. Each patient was supplied with the standard asthma diary used in our clinic, in which a score is given for nocturnal cough or wheeze, daytime cough or wheeze and limitation of normal activities, with a maximum possible daily score of 12. The dose of any medication taken and the number of doses per $24 \mathrm{~h}$ were also recorded. Short-acting inhaled bronchodilators were used as rescue medication during the course of the study. No separate record was made of bronchodilator use before exercise.

Table 1. - Age, sex and baseline lung function data of the subjects in the three study groups

\begin{tabular}{|c|c|c|c|c|c|}
\hline & & $\begin{array}{l}\text { Mild } \\
(\mathrm{n}=9)\end{array}$ & $\begin{array}{l}\text { Moderate } \\
\quad(\mathrm{n}=9)\end{array}$ & & $\begin{array}{l}\text { Severe } \\
(\mathrm{n}=10)\end{array}$ \\
\hline $\begin{array}{ll}\operatorname{Sex} & M / F\end{array}$ & & $2 / 7$ & $6 / 3$ & & $7 / 3$ \\
\hline Age yrs & 12 & $(10-13)$ & $13(11-15)$ & 12 & $(9-15)$ \\
\hline PEF \% pred & 87 & (80-95) & $85 \quad(72-99)$ & 90 & $(83-97)$ \\
\hline $\mathrm{FEV}_{1} \%$ pred & 82 & (74-89) & $76(67-84)$ & 81 & $(75-87)$ \\
\hline MEF50 \% pred & 77 & (57-97) & $60(49-71)$ & 66 & $(46-85)$ \\
\hline (HI-LO) VRB \% & 13 & $(7-19)$ & $10 \quad(6-14)$ & 12 & $(7-17)$ \\
\hline Days of observation & 81 & $(76-86)$ & $81(77-84)$ & 84 & $(80-89)$ \\
\hline
\end{tabular}

Values are presented as mean, and $95 \%$ confidence interval in parenthesis. HI-LO VRB: mean of daily diurnal PEF variation over 12 weeks of study (see analysis of data section for further definition). M: male; F: female; PEF: peak expiratory flow; \% pred: percentage of predicted value; FEV1: forced expiratory volume in one second; MEF50: maximal expiratory flow at $50 \%$ forced vital capacity. 


\section{Data recorded in the laboratory}

At each of the seven visits to the department, the patient was examined and asked to indicate the subjective severity of asthma over the previous $4 \mathrm{~h}$ using a visual analogue score for each symptom of wheeze, tightness, breathlessness and cough, with a maximum combined symptom score of 20. Lung function was measured at least 4 $\mathrm{h}$ after the last dose of any bronchodilator medication using a Vitalograph Compact electronic spirometer (Vitalograph Ltd, Buckingham, UK), with the patient making at least three attempts at performing spirometry. The best flow-volume curve, defined as that with the largest value for the sum of forced vital capacity and FEV1, was accepted and the values of PEF, FEV1, and maximal expiratory flow at $50 \%$ forced vital capacity (MEF50) from this curve were taken as the result. In addition, the patient was asked to use his/her own PEF meter in the laboratory and the best of three attempts was recorded as the result. At the conclusion of the clinic visit, treatment was adjusted if necessary in accordance with normal clinical practice. Patients were encouraged to call the physician between clinic visits if they had any problems.

\section{Analysis of data}

The diary record of symptoms, drug consumption, morning and evening PEF and the results obtained during the visits to the department every 2 weeks were stored on a computer spread sheet for analysis. All values for lung function were normalized by expressing them as percentage of predicted normal for each patient using the appropriate European Coal and Steel Community (ECCS) normal data. The diurnal variation in PEF on a day-today basis, the (HI-LO) VRB index, was calculated as described by AlBERTINI et al. [12] and recommended in the international consensus report on the diagnosis and treatment of asthma [4], where:

\section{$(\mathrm{HI}-\mathrm{LO}) \mathrm{VRB}=($ highest $\mathrm{PEF}-$ lowest $\mathrm{PEF}) /($ highest $\mathrm{PEF}$ + lowest PEF) $\times 200 \%$}

This index is identical to the term "amplitude percent mean" used by some authors.

Because of the subjective nature of symptom scores and the variability of asthma both within and between subjects, the major analysis comprised correlations between various parameters for each individual subject. Correlations were considered significant and meaningful if the p-value was less than 0.05 and if the relationship was logical, e.g. if the correlation between PEF and diary score was both significant and negative. If the relationship was illogical, e.g. the correlation between PEF and diary score was significant but positive, the correlation was taken as meaningless. The number of subjects within each group with significant meaningful correlations for the parameters in question was then determined and a Chi-squared analysis was used to determine the significance of differences in the proportion of meaningful correlations between the groups.

The diary of each patient, including the recorded PEF values and drug consumption, was reviewed independently by three experienced paediatric pulmonologists, who marked the days on which they thought the patient was symptomatic. A sick day was recorded in the data base of the patient when at least two out of the three physicians were in agreement. Subsequently, a computer algorithm was constructed by trial and error to match the physiciandefined sick days as closely as possible for the whole group but using symptom scores and rescue drug consumption only. This algorithm was then used to define sick days for each individual patient, and a subgroup of 14 patients were identified who were sick on at least 7 days during the study.

For normally distributed parameters, such as baseline lung function, the Student's t-test was used to determine the significance of differences between groups and nonparametric statistics were used when the data were not normally distributed. In order to compare measurements of PEF made with the mini-Wright meter and those made with the Vitalograph spirometer, the technique of BLAND and Altman [13] was used, which involves considering the importance of the standard deviation of mean differences.

\section{Results}

A total of 28 patients completed the full 12 week study, and at the end nine were classified as mild, nine moderate and 10 severe asthmatics (table 1). There were more girls in the mild group and more boys in the severe group but there was no significant difference in the ages between the groups. The initial lung function recorded in the laboratory on entry to the study was similar in all three groups, as was the mean diurnal variation in PEF (HI-LO)VRB for the whole period of observation. The average number of days of observation was 82 out of a theoretical total of $84(98 \%)$, the difference being due to lack of recording on a few days in some patients. There were no significant differences in the number of days of recording between the groups. All but one of the final mild group were initially recruited as mild asthmatics, all of the final moderate group were initially recruited as moderate asthmatics, and all of the final severe group as severe asthmatics. Only one initially moderate asthmatic was reclassified as a mild asthmatic by the end of the study. There were no differences in the results of the three young adults compared with those of the children in the same group.

The typical patterns of response found in two patients can be seen in figure 1 and 2. Patient No. 1 (from the severe group) (fig. 1) showed a good correlation between the daily diary score and PEF $(\mathrm{r}=0.78 ; \mathrm{p}<0.0001)$. Of the total group of 28 patients, 17 behaved in this fashion, with a significant correlation between daily diary score and mean daily PEF. However, in most patients, the FEV1 and MEF50 measured in the laboratory every 2 weeks bore no relation to either diary scores, PEF or to each other, as shown for patient No.1 in figure 1 . Patient No. 2 (from the mild group) was typical of the 11 patients in whom there was no significant correlation $(\mathrm{r}=0.02 ; \mathrm{p}=0.88)$ between daily diary score and mean daily PEF (fig. 2). This patient had higher PEF values and fewer symptoms than patient No. 1 and the PEF remained consistently near to or above $100 \%$ predicted 
a) Pt No. 1

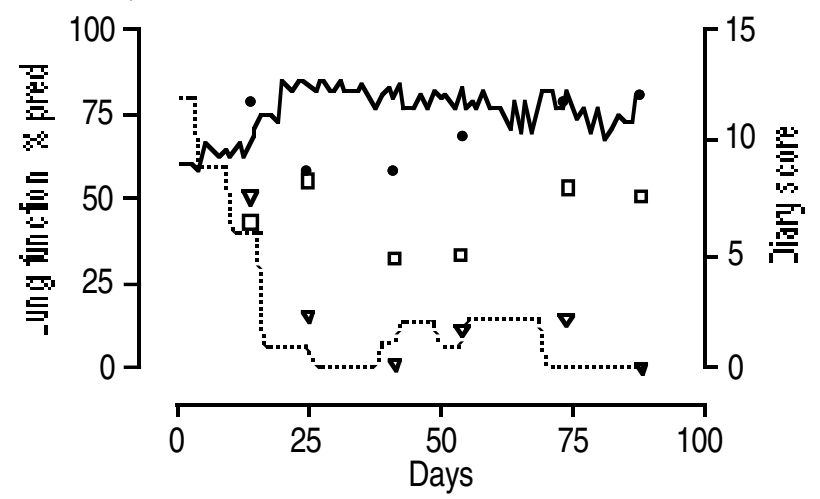

b) Pt No. 1

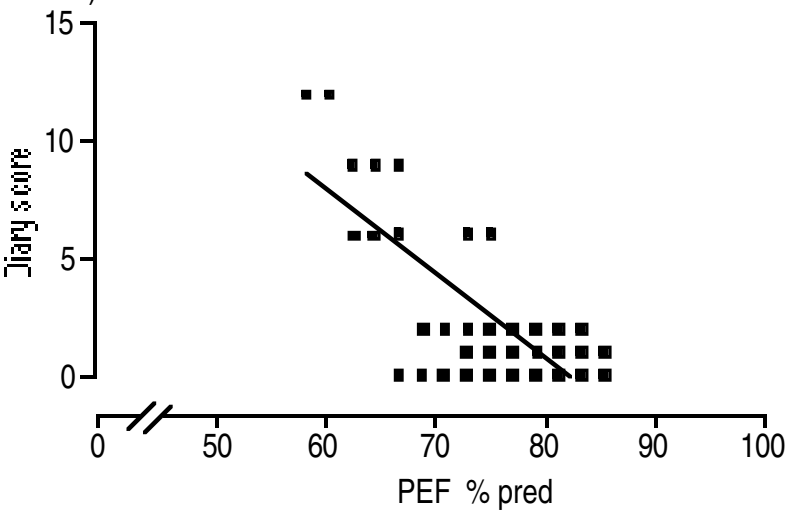

Fig. 1. - a) Example of day-to-day record of PEF (mean of morning and evening values) and total symptom scores for patient No. 1 (severe group). In addition, the average diary score for each 2 week period is shown together with the FEV1 and MEF50 recorded at the laboratory at the end of the 2 week period. b) Correlation between total daily diary score and mean of twice daily PEF for the whole study for patient No. 1 . The correlation was significant $(\mathrm{r}=0.78$; $\mathrm{p}<0.0001)$. - - : daily PEF; ---: daily diary score; $\mathbf{\nabla}$ : average 2 week diary score; $\bullet$ : laboratory FEV $_{1}$; $\square$ : laboratory MEF50. PEF: peak expiratory flow; $\mathrm{FEV}_{1}$ : forced expiratory volume in one second; MEF50: maximal expiratory flow at 50\% forced vital capacity; $\%$ pred: percentage of predicted value; Pt: patient.

despite the brief attacks of asthma shown by the symptom scores. Laboratory measurements of FEV1 and MEF50 also remained constant and were considerably lower than PEF expressed as percentage predicted.

Measurements at the seven visits to the lung function laboratory

$P E F$ meter versus PEF spirometer. The PEF meter yielded values for PEF which were on average $5-10 \%$ predicted higher than the values from the spirometer. For the mild, moderate and severe groups, the mean (SD) differences were 12.4 (8.4), 10.7 (13.1) and 5.5 (7.7) \% pred, respectively. Using the method of BLAND and ALTMAN [13], it was proposed that the two devices would give clinically similar values if the SD of mean differences was $<7.35 \%$ pred, i.e. $95 \%$ of paired values would lie within a range of $30 \%$ predicted. In only five $(56 \%)$ of the mild group, $1(11 \%)$ of the moderate group and 2 $(20 \%)$ of the severe group was this the case, so that for 20 out of 28 subjects the agreement between the PEF meter readings and those from the spirometer in the laboratory were very poor. a) Pt No. 2

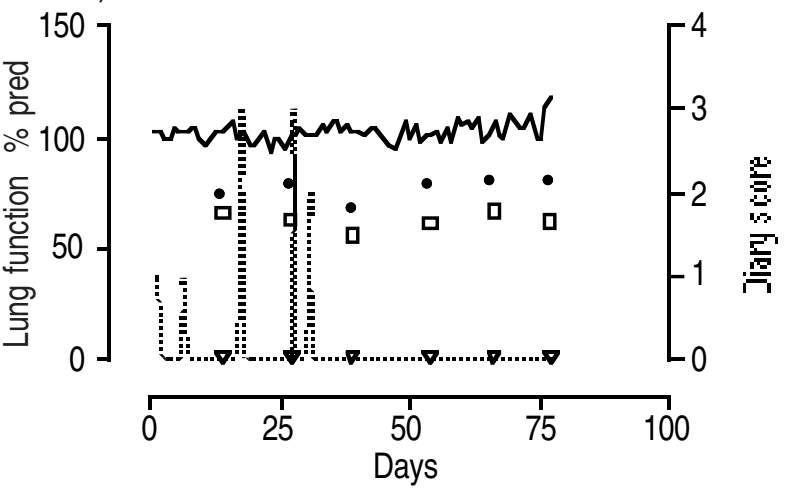

b) Pt No. 2

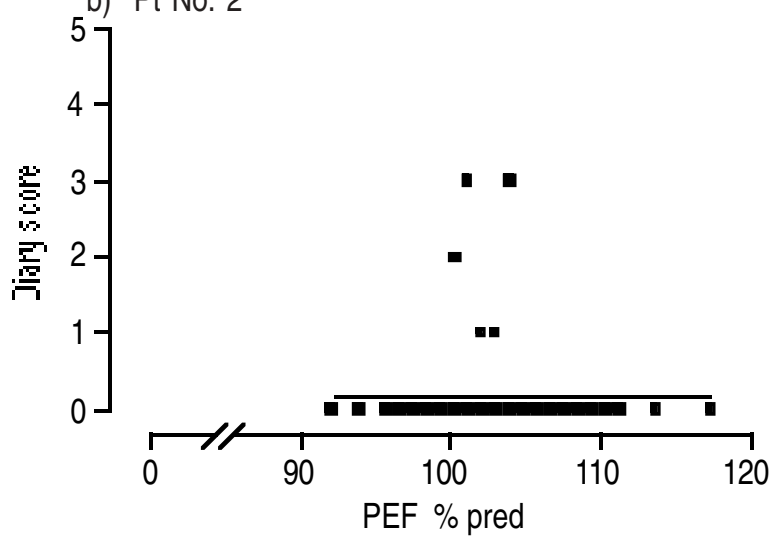

Fig. 2. - a) Example of day-to-day record of PEF (mean of morning and evening values) and total symptom scores for patient No. 2 (mild group). In addition, the average diary score for each 2 week period is shown together with the FEV1 and MEF50 recorded at the laboratory at the end of the 2 week period. The brief asthma attacks shown by the change in diary score were not associated with changes in daily PEF or measurement of lung function at the end of the two week period. b) Correlation between total daily diary score and mean of twice daily PEF for the whole study for patient No. 2. The correlation was not significant $(\mathrm{r}=0.02 ; \mathrm{p}=0.88)$. — : daily PEF; ---: daily diary score; $\mathbf{\nabla}$ : average 2 week diary score; $\bullet$ : laboratory FEV1; 口: laboratory MEF50. Note difference in diary score axis compared to Fig. 1 (severe group). For further abbreviations see legend to figure

Lung function correlations and symptoms. As shown in table 2, the proportion of each group with significant correlations between the various lung function parameters was low, apart from that between FEV1 and MEF50 in the moderate and severe groups and between PEF from the spirometer and FEV 1 in the severe group. Using the Chi-squared analysis, none of the differences between the groups was significant. The proportion of significant correlations for all three groups combined was significantly greater $(\mathrm{p}<0.01)$ for FEV1 vs MEF50 than for PEF vs MEF50. The correlation between the subjective asthma symptoms of the patient as reflected in the visual analogue score in the laboratory and the objective measurements of lung function at the same time was extremely poor in all groups.

Comparisons between averaged diary record and lung function laboratory data

In order to determine to what degree measurements of lung function in the laboratory reflected the average 
Table 2. - Proportion of patients (as percentage of each group) with significant correlations for measurements made at the seven visits to the laboratory at intervals of 2 weeks

\begin{tabular}{lccc}
\hline & Mild & Moderate & Severe \\
\hline PEFsp vs FEV1 & 56 & 33 & 60 \\
PEFsp vs MEF50 & 33 & 33 & 30 \\
FEV1 $v$ s MEF50 & 56 & 67 & 80 \\
PEFsp vs VAS & 0 & 11 & 30 \\
FEV1 $v$ s VAS & 0 & 11 & 10 \\
MEF50 vs VAS & 0 & 22 & 20 \\
\hline
\end{tabular}

PEFsp: PEF measured using the spirometer; VAS: visual analogue score. For further abbreviations see legend to table 1 .

symptoms, home PEF recording and drug consumption over the previous 2 weeks, correlations were performed for each subject between the averaged diary data in each of the six periods of two weeks and the measurements of lung function in the laboratory at the end of each 2 week period. As can be seen from table 3, the proportion of each group with significant correlations between the averaged diary data and the lung function measured in the laboratory was extremely low. Significant correlations between diurnal PEF variation and lung function were even fewer and are not shown in table 3 . There were no significant differences between the groups in any of these proportions.

Comparisons between symptoms, PEF and drug consumption on a day-to-day basis

The data from the diary record of symptoms, twice daily PEF and drug consumption for the whole 12 week period were examined for meaningful significant correlations for each patient. As shown in table 4, there were significant correlations between the symptom score, mean daily PEF and rescue bronchodilator use in $22-56 \%$ of the mild and moderate groups, but in $70-80 \%$ of the severe group. The total number of these correlations was significantly greater in the severe group compared both with the moderate group $(\mathrm{p}=0.01)$ and the mild group $(\mathrm{p}=0.003)$. For the individual correlations, the numbers were small but the difference between the severe and mild groups was significant $(\mathrm{p}=0.04)$ for bronchodilator use versus both symptoms and PEF. Diurnal PEF variation, calculated as the (HI-LO)VRB index, correlated

Table 3. - Proportion of patients (as percentage of each group) with significant correlations between measurements made at the six visits to the laboratory at intervals of 2 weeks and the average data for the previous 2 weeks recorded in the diary

\begin{tabular}{lccc}
\hline & Mild & Moderate & Severe \\
\hline PEFsp vs PEFday & 11 & 11 & 20 \\
MEF50 vs PEFday & 22 & 0 & 10 \\
FEV1 vs PEFday & 33 & 0 & 10 \\
PEFsp vs SYMP & 22 & 0 & 10 \\
FEV1 vs SYMP & 44 & 0 & 10 \\
MEF50 vs SYMP & 22 & 0 & 10 \\
\hline
\end{tabular}

PEFsp: PEF measured using the spirometer; PEFday: average of twice daily PEF recorded for 2 week periods at home; SYMP: average of daily symptom score recorded for 2 week periods at home. For further abbreviations see legend to table 1. poorly with symptoms and bronchodilator use, with the highest proportion (40\%) of significant correlations being between diurnal variation and symptoms in the severe group, but differences between the groups was not significant. The data were examined to see if there was any consistent pattern of time lag between change in symptoms and change in PEF but none was discernible.

\section{Well versus sick days}

Using the computer algorithm, 1 of the 9 patients in the mild group, 4 of the 9 in the moderate, group and 9 of the 10 in the severe group were sick on at least 7 days (mean number of sick days 19). The mean (95\% $\mathrm{CI}$ ) daily PEF as percentage predicted on sick days in this group was significantly lower than on well days (82\% (71-93\%) and 96\% (88-104\%), respectively). The difference in mean PEF between well and sick days was relatively small (mean 14\%; 95\% CI 8-20). Diurnal variation in PEF, expressed as (HI-LO)VRB, was not significantly different between the well and sick days, even though it was higher on average on sick days (12 vs $8 \%)$.

\section{Discussion}

This study has shown that in children and young adults with severe asthma there are significant intra-individual correlations between ambulatory measurement of PEF, symptoms, and rescue bronchodilator consumption on a day-to-day basis. Such correlations are less common in children with mild-to-moderate asthma. In all types of asthmatics, there is little or no correlation between lung function measured in the laboratory and ambulatory data collected over the previous 2 weeks.

Previous studies of the relationship between PEF and clinical parameters in asthmatics have not yielded consistent results. In a study of asthmatic children residing in an institution for 3 months, PERRIN et al. [14] reported a very high correlation between PEF measured four times daily and the time since the last episode of wheezing. However, it appears that they pooled the data from all 42 children, giving a very large number of data points, and they did not look at individual correlations. Moreover, all children were admitted to the hospital and given additional treatment because they had been uncontrolled as out-patients, so that improvement in all parameters was to be expected. In a study more similar to the present study, APTER et al. [15] observed 13 asthmatic adults over 9 weeks, during which they measured PEF at home every morning and recorded symptoms and drug consumption in a diary. Their patients would have fallen into our moderate-to-severe asthma groups. They found no correlations on an individual basis between the various parameters in four subjects, a significant correlation between PEF and symptoms in eight and between $\mathrm{PEF}$ and rescue bronchodilator in four. These results are similar to those of our moderate group.

Previous studies of the value of daily PEF recording have not specifically addressed the question of the influence of the clinical severity of the asthma on the results. Some have compared diurnal PEF variation with other indices of bronchial reactivity, and the correlations have 
Table 4. - Proportion of patients (as percentage of each group) with significant correlations between measurements made on a day-to-day basis at home over the whole 12 week period of observation

\begin{tabular}{lcccc}
\hline & Mild & Moderate & Severe & Significance \\
\hline PEF vs SYMP & 56 & 44 & 80 & $*$ \\
PEF vs BD & 22 & 33 & 70 & $* *$ \\
SYMP $v$ s BD & 33 & 56 & 80 & $* *$ \\
(HI-LO) VRB vs SYMP & 22 & 11 & 40 & NS \\
(HI-LO) VRB vs BD & 33 & 11 & 20 & Ns \\
\hline
\end{tabular}

PEF: peak expiratory flow; SYMP: daily symptom score; BD: number of puffs of rescue bronchodilator taken per day; (HI-LO) VRB: diurnal PEF variation. *: significant difference between moderate and severe groups; $* *$ : significant difference between mild and severe groups; Ns: no significant differences between groups.

been poor in some $[16,17]$ and better in others $[18,19]$. Comparisons between diurnal variation in PEF and asthma symptoms or drug consumption have mostly yielded very poor correlations $[17,18]$. The poor correlation between periodic laboratory measurements of lung function in asthmatic children and the recording of PEF at home over the previous 2 weeks was reported by FERGUSON [10], and the discrepancy between laboratory measurement of PEF and other indices of lung function in asymptomatic asthmatic children has also been noted [20]. Part of the problem with PEF measurement may lie with its inability to reflect the severity of asthma involving the smaller intrathoracic airways. Analyses of the relationship between forced expired flow and volume suggest that the PEF is effort-dependent and reflects large airway function, whilst the MEF50 is much less effortdependent and reflects small airway function [21-23].

The present study was designed to mimic the clinical situation as closely as possible in order to explore the relationship between the various parameters used in clinical practice to evaluate children and young people with asthma. No attempt was made to interfere with normal clinical practice, other than to have the patient attend the clinic every 2 weeks, which is more frequent than would normally be required for management. The patients were aware of their PEF measurements and this could have influenced their reporting of symptoms but this is exactly the situation which exists in everyday practice. Compliance during this type of study is always problematical. Using various types of detection device, it has been shown that asthmatic patients frequently fail to take prescribed medication and forge entries in their asthma diaries. CoutTs et al. [24] showed that his patients exaggerated the number of doses of medication actually consumed by about 20\%, whilst CHOwIENCZYK et al. [25] found that about $26 \%$ of diary entries were either faked or entered retrospectively. APTER et al. [15] reported that their patients took on average only $64 \%$ of the prescribed dose of inhaled steroid. Our patients recorded data in their diaries on $98 \%$ of the theoretically possible number of days over the 3 months of observation but it would be unreasonable to assume that none of our patients forged some of the diary and we have no way of checking this.

It is possible that we should have obtained greater correlation between the various parameters with larger numbers of observations - at least as far as the comparisons between laboratory tests and the mean of 2 week observations are concerned, since there were only seven laboratory visits for each patient and six 2 week periods of observation. A significant correlation coefficient at the $5 \%$ level for 6-7 points is approximately 0.75 , whereas it is only approximately 0.22 for the $80-90$ points in the day-to-day correlations. The averaging of ambulatory data over two week periods for comparison with the laboratory measurements could also have reduced the variability of the data and the possibility of finding significant correlations. Indeed, SIERSTED et al. [26] showed that important information on sporadic low readings of PEF was lost by averaging data over 2 weeks.

The poor correlation between PEF recorded in the laboratory by the PEF meter and by spirometry in 20 of our 28 patients was initially surprising but in fact a very similar conclusion was reached by SLY et al. [27], who followed 12 asthmatic boys for 3 months and measured their PEF twice daily with various PEF meters and compared it with the PEF measured by spirometry. The same PEF meter as used in the present study detected only 6 out of 19 exacerbations of asthma noted by a physician based on the PEF measured by spirometry, although a statistical analysis was not performed. In both studies, the PEF meter gave a higher reading on average. It is quite possible that the PEF meter and spirometer may not be measuring quite the same thing in asthmatic children, or that the results are affected by the different techniques used by the patients when performing the tests.

The analysis of correlations in the present study was based on the finding of a significant value for the correlation coefficient together with a relationship between the parameters which was logical. A similar approach was used by APTER et al. [15] to exclude data for one correlation which was significant but illogical. In the comparison between measurements made every 2 weeks in the laboratory there was a significant but illogical correlation in only one patient in the moderate group for MEF50 versus the visual analogue symptom score. In the comparison between laboratory data and those collected at home over the previous 2 weeks, there were six significant but illogical correlations in the mild group, one in the moderate group and five in the severe group for different parameters, which emphasizes the poor relationship between laboratory and ambulatory measurements. In the day-by-day correlations for the whole 12 weeks of the study, there was one significant but illogical correlation in the mild group, four in the moderate group and one in the severe group.

Much has been made of diurnal variation of PEF as an index of the adequacy of control in asthmatic patients 
and this concept has been accepted by those compiling guidelines for asthma management in adults and children [4-6]. Most studies have reported greater diurnal variation in PEF both in adults and children with asthma using the (HI-LO)VRB index [12, 19, 28-30]. However, HENDERSON and CARSwEll [31] found mean values of $8.8 \%$ in normal children and $12.5 \%$ in asthmatics - a smaller difference than in adults and similar to the low PEF variation in the present study. It may be that PEF variation is less marked in children and young people, and moreover a recent study by FRISCHER et al. [30] found $\mathrm{PEF}$ variation to have low reproducibility in young children and a low sensitivity for diagnosing asthma.

The definition of sick and well days by the computer algorithm (using symptoms and drug consumption only) is of limited value since it was derived from the review by physicians of all the diary record including the PEF data. Even so, given the probable tendency of the physician to define a day as a sick day when the PEF was low, the small difference in PEF between well and sick days (mean $14 \%$ pred) is likely, if anything, to overestimate the difference and suggests that PEF recording is relatively insensitive to changes in the clinical state.

In the ultimate analysis, the question is whether the measurement of PEF at home on a day-to-day basis added anything to the evaluation of the patients in this study. Given the good individual correlations between mean daily PEF and both symptoms and rescue bronchodilator consumption in the severe group and the relatively small difference in PEF between well and sick days in those patients who were sick for almost a quarter of the observation period, it could be argued that the daily record was adequate without the PEF measurements for severe or sick patients. For the mild and moderate patients, the correlations were so poor and the control so good that it is doubtful whether either the diary or PEF measurement added anything to management.

There have been several recent studies which have cast doubt on the value of ambulatory or frequent PEF recording for the management of asthma. CHARLton et al. [8] followed 115 asthmatic adults and children for a year, with one group using an action plan for treatment based on symptoms alone and the other using a PEF meter in addition as suggested by BEASLEY et al. [32]. Control of the asthma improved in both groups with a reduction in consultations with the physician, in the number of courses of rescue corticosteroids and the use of rescue bronchodilator, and there was no difference between those who used the PEF meter and those who did not. MALO et al. [9] investigated 60 adult asthmatics who used an asthma diary for 6 months and ambulatory PEF recording for 6 months in a cross-over study, with the patients being asked to report to the clinic when they had an exacerbation of asthma. Of the total exacerbations, $69 \%$ occurred when using a diary alone and $75 \%$ when using a PEF meter, and the conclusion was that using a simple asthma diary was as effective as home monitoring of PEF.

In conclusion, this study has shown that PEF measured twice daily at home correlates well with clinical indices of asthma and rescue bronchodilator consumption in those with more severe disease but poorly in those with mild asthma. In most subjects, measurements made at intervals of 2 weeks in the laboratory do not reflect the mean symptom scores, rescue bronchodilator consumption or PEF values in the previous 2 weeks. Peak expiratory flow recorded by a peak flow meter does not necessarily reflect the peak expiratory flow measured by spirometry. Better methods of obtaining objective information on the status of ambulatory patients is required, especially for the less severe asthmatics, possibly by real time monitoring of the forced expiratory flow volume curve, symptoms and drug consumption.

Acknowledgement: This study was undertaken with the help of a grant from Glaxo, UK and the authors wish to express their sincere appreciation to Glaxo for making the study possible.

\section{References}

1. Sly PD, Landau LI, Weymouth R. Home recording of peak expiratory flow rates and perception of asthma. Am J Dis Child 1985; 139: 479-482.

2. Hetzel MR, Clark TJH. Comparison of normal and asthmatic circadian rhythms in peak expiratory flow rate. Thorax 1980; 35: 732-738.

3. Ryan G, Latimer KM, Dolovich J, Hargreave FE. Bronchial responsiveness to histamine: relationship to diurnal variation of peak flow rate, improvement after bronchodilator and airway calibre. Thorax 1982; 37: 423-429.

4. International consensus report on diagnosis and treatment of asthma. Eur Respir J 1992; 5: 601-641.

5. Guidelines on the management of asthma. Thorax 1993; 48: (Suppl.): S1-S24.

6. Asthma: a follow-up statement from an International Paediatric Asthma Consensus Group. Arch Dis Child 1992; 67: 240-248.

7. Clark NM, Evans D, Mellins RB. Patient use of peak flow monitoring. Am Rev Respir Dis 1992; 145: 722-725.

8. Charlton I, Charlton G, Broomfield J, Mullee MA. Evaluation of peak flow and symptoms only self-management plans for control of asthma in general practice. Br Med J 1990; 301: 1355-1359.

9. Malo J-L, L'Archeveque J, Trudeau RT, d'Aquino C, Cartier A. Should we monitor peak expiratory flow rates or record symptoms with a simple diary in the management of asthma. J Allergy Clin Immunol 1993; 91: 702-709.

10. Ferguson AC. Persisting airway obstruction in asymptomatic children with asthma with normal peak expiratory flow rates. J Allergy Clin Immunol 1988; 82: 19-22.

11. Chai H, Purcell K, Brady K, Falliers CJ. Therapeutic and investigational evaluation of asthmatic children. $J$ Allergy 1968; 41: 23-36.

12. Albertini M, Politano S, Berard E, Boutte P, Mariani R. Variation in peak expiratory flow of normal and asymptomatic asthmatic children. Pediatr Pulmonol 1989; 7 : 140-144.

13. Bland MR, Altman DG. Statistical methods for assessing agreement between two methods of clinical measurement. Lancet 1986; 1: 307-310.

14. Perrin PV, Weldon D, McGeady SJ. Objective indicators of severity of asthma. J Allergy Clin Immunol 1994; 94: 517-522.

15. Apter AJ, ZuWallack RL, Clive J. Common measures of asthma severity lack association for describing its clinical course. J Allergy Clin Immunol 1994; 94: 732-737.

16. Higgins BG, Britton JR, Chinn S, Cooper S, Burney PGJ, Tattersfield AE. Comparison of bronchial reactivity and 
peak expiratory flow variability measurements for epidemiologic studies. Am Rev Respir Dis 1992; 145: 588-593.

17. Kerstjens HAM, Brand PLP, de Jong PM, Koeter GH, Postma DS, and the Dutch CNSLD study group. Influence of treatment on peak expiratory flow and its relation to airway hyperresponsiveness and symptoms. Thorax 1994; 49: 1109-1115.

18. Gern JE, Eggleston PA, Schuberth KC, et al. Peak flow variation in childhood asthma: a three year analysis. $J$ Allergy Clin Immunol 1994; 93: 706-716.

19. Troyanov S, Ghezzo H, Cartier A, Malo J-L. Comparison of circadian variations using FEV1 and peak expiratory flow rates among normal and asthmatic subjects. Thorax 1994; 49: 775-780.

20. Bye MR, Kerstein D, Barsh E. The importance of spirometry in the assessment of childhood asthma. Am J Dis Child 1992; 146: 977-978.

21. Fry DL, Hyatt RE. Pulmonary mechanics: a unified analysis of the relationship between pressure, volume and gas flow in the lungs of normal and diseased human subjects. Am J Med 1960; 29: 672-689.

22. Mead J, Turner JM, Macklem PT, Little JB. Significance of the relationship between lung recoil and maximum expiratory flow. J Appl Physiol 1967; 22: 95-108.

23. Mead J. Expiratory flow limitation: a physiologist's point of view. Fed Proc 1980; 39: 2771-2775.

24. Coutts JAP, Gibson NA, Paton JY. Measuring compliance with inhaled medication in asthma. Arch Dis Child 1992; 67: 332-333.

25. Chowienczyk PJ, Parkin DH, Lawson CP, Cochrane GM. Do asthmatic patients correctly record home spirometry measurements? Br Med J 1994; 309: 1618.

26. Siersted HC, Hansen HS, Hansen N-CG, Hyldebrandt N, Mostgard G, Oxhoj H. Evaluation of peak expiratory flow variability in an adolescent population sample. Am J Respir Crit Care Med 1994; 149: 598-603.

27. Sly P, Cahill P, Willet K, Burton P. Accuracy of mini peak flow meters in indicating changes in lung function in children with asthma. Br Med J 1994; 308: 572-574.

28. Frischer Th, Kuhr J, Meinert R, Karmaus W, Forster J, Urbanek R. Relation between response to exercise and diurnal variability of peak expiratory flow rate in primary school children. Thorax 1993; 48: 249-253.

29. Quackenboss JJ, Lebowitz MD, Krzyzanowski M. The normal range of diurnal changes in peak expiratory flow rates. Am Rev Respir Dis 1991; 143: 323-330.

30. Frischer T, Meinert R, Urbanek R, Kuehr J. Variability of peak expiratory flow rate in children: short and long term reproducibility. Thorax 1995; 50: 35-39.

31. Henderson AJ, Carswell F. Circadian rhythm of peak expiratory flow in asthmatic and normal children. Thorax 1989; 44: 410-414.

32. Beasley R, Cushley M, Holgate ST. A self-management plan in the treatment of adult asthma. Thorax 1989; 44: 200-204. 